Review

\title{
Parabens in male infertility-Is there a mitochondrial connection?
}

\author{
Renata S. Tavares ${ }^{\mathrm{a}}$, Fátima C. Martins ${ }^{\mathrm{b}}$, Paulo J. Oliveira ${ }^{\mathrm{a}}$, João Ramalho-Santos ${ }^{\mathrm{a}}$, Francisco P. Peixoto ${ }^{\mathrm{b}, *}$ \\ a Department of Zoology, Center for Neuroscience and Cell Biology of Coimbra, University of Coimbra, 3004-517 Coimbra, Portugal \\ b Chemistry Department, CECAV, University of Trás-os-Montes and Alto Douro, 5001-801 Vila Real, Portugal
}

\section{A R T I C L E I N F O}

\section{Article history:}

Received 4 March 2008

Received in revised form 16 September 2008

Accepted 10 October 2008

Available online 21 October 2008

\section{Keywords:}

Parabens

Mitochondria

Rat testis

Infertility

Male

\begin{abstract}
A B S T R A C T
Parabens are widely used as preservatives in many foods, cosmetics, toiletries, and pharmaceuticals due to their relatively low toxicity profile and to a long history of safe use. Parabens are alkyl esters of $p$ hydroxybenzoic acid and typically include methylparaben, ethylparaben, propylparaben, butylparaben, isobutylparaben, isopropylparaben and benzylparaben. These compounds are known to have a null or very weak estrogenic activity in estrogen receptor assays in vitro. In recent years, an increasing concern has emerged regarding possible adverse effects of chemicals in food and in cosmetics on human reproduction outcomes. In developed countries about $15 \%$ of human couples are affected by infertility, almost half of these cases attributed to men, through low sperm motility or/and sperm count. It is known that a significant number of cases of male infertility results from exposure to xenobiotics, and also that testis mitochondria are particularly affected by drug-induced toxicity. The present review discusses evidence that parabens may not be as safe as initially thought, and suggests that the interaction between parabens and mitochondrial function in the testis may be key in explaining the contribution of parabens for a decrease in reproductive potential.
\end{abstract}

(C) 2008 Elsevier Inc. All rights reserved.

\section{Contents}

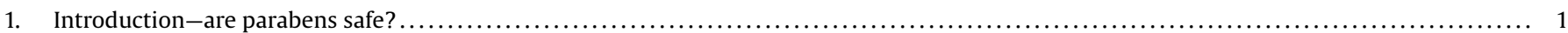

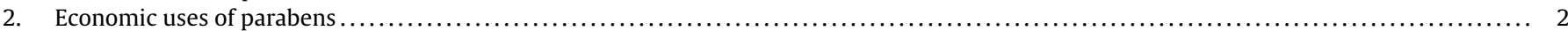

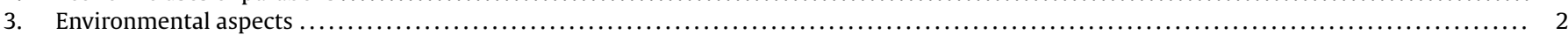

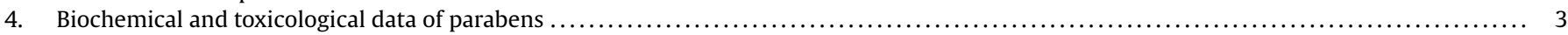

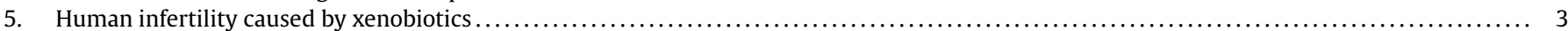

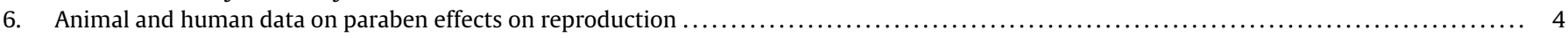

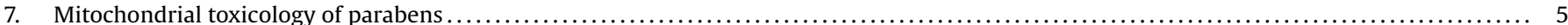

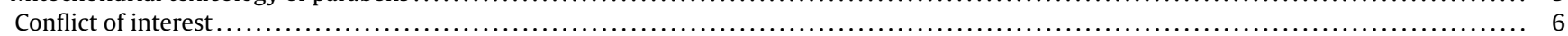

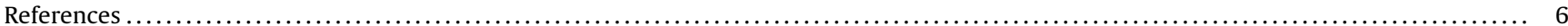

\section{Introduction-are parabens safe?}

The purpose of the present review is to propose that parabens may be implicated in male infertility and discuss the possible involvement of mitochondrial dysfunction in this process, questioning in the process if such molecules pose risks to human health.

Parabens are also designated as esters of $p$-hydroxybenzoic acid. The most commonly found parabens are methyl-, ethyl-, propyl- and butylparaben (Fig. 1). Parabens are extensively used as

\footnotetext{
* Corresponding author. Tel.: +351 259350242; fax: +351 259350480

E-mail address: fpeixoto@utad.pt (F.P. Peixoto).
}

antimicrobial preservatives in food, cosmetics and pharmaceutical products due to their broad spectrum of activity, inertness and low cost. Parabens also congregate several criteria for an ideal preservative: they are stable and effective over an extensive $\mathrm{pH}$ range, sufficiently soluble in water to produce an effective concentration in aqueous phase, have no perceptible odor or taste, no induction of discoloration and stability over broad $\mathrm{pH}$ and heat ranges [1]. Parabens are lipophilic compounds with increasing octanol/water partition coefficients (expressed as $\log K_{\mathrm{ow}}$, Table 1 ) as the carbon number of the alkyl chain of parabens increases. Antimicrobial activity of parabens increases with the length of alkyl grouping from methyl to $n$-butyl [2]. Since microbial replication generally occurs in the water phase of oil/water bases, the amount of paraben dis- 


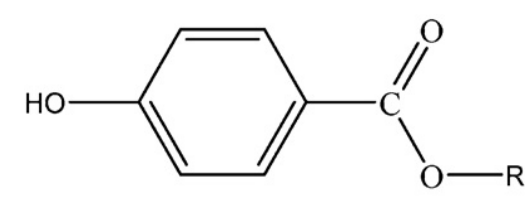

Fig. 1. Chemical structure of parabens; $\mathrm{R}=\mathrm{H}$ ( $p$-hydroxybenzoic acid), $\mathrm{R}=\mathrm{CH}_{3}$ (methylparaben), $\mathrm{R}=\mathrm{C}_{2} \mathrm{H}_{5}$ (ethylparaben), $\mathrm{R}=\mathrm{C}_{3} \mathrm{H}_{7}$ (propylparaben), and $\mathrm{R}=\mathrm{C}_{4} \mathrm{H}_{9}$ (butylparaben).

solved in the water phase generally determines the preservative efficiency; for such reason, in order to increase the ability of the system to withstand microbial contamination, it is common to find combinations of two or more paraben homologues within a single product [3].

Parabens are generally considered as safe preservatives, since they are rapidly absorbed and metabolized into $p$-hydroxybenzoic acid, which is less toxic than the parent compounds, and is therefore consumed in large quantities in a daily basis. Because of their widespread use, the potential toxicity of parabens has been studied both in vivo and in vitro to assess a variety of toxicological aspects [4]. Although parabens have been used for more than 50 years and are generally considered as safe, several studies concerning on the safety of parabens have been published [5-10]. Recent reports indicate that exposure to parabens modulate or disrupt the endocrine system and thus may have harmful consequences on animal and human health. Some studies have demonstrated that parabens possess low estrogenic activity [11], and, since the breast is an endocrine-sensitive organ exposed to a wide range of estrogenic agents, an association between the use of underarm cosmetics containing parabens, such as deodorants and antiperspirants, and an increased incidence of breast cancer was made [12,13]. In fact, a study within a population of breast cancer patients showed that those who were diagnosed with breast cancer at an earlier age used more antiperspirant/deodorant products [14]. Furthermore, there are other reports on the estrogenic activity of several parabens in human breast cancer cells [15-18], and in vivo [17,18]. Both isobutyl- and benzylparaben caused an uterotrophic response in mice following a subcutaneous injection and a topical administration, respectively [17,18]. Nevertheless, another study concerning the relative use of antiperspirant/deodorant products reported no difference between a control group and a group of breast cancer patients [19]. As the breast is exposed to a wide range of estrogenic chemicals, further rigorous studies are needed to determine the relevance of parabens in breast cancer.

Additionally, some recent studies have reported adverse reproductive effects of parabens [20-22].

Energy metabolism is the fundamental process supporting all cell functions and is crucially important in sperm, which are specialized motile cells that have to move rapidly to encounter and fertilize the oocyte. To this regard sperm need exceptionally more ATP than any other cell.

Inhibitory effects of parabens on mitochondrial respiratory capacities have been known since 1998 [23]. Martins et al. [24] have also demonstrated that parabens inhibit respiration and depress

Table 1

$\log K_{\text {ow }}$ of parabens.

\begin{tabular}{lll}
\hline Parabens & CAS number & $\begin{array}{l}\text { Log } n \text {-octanol/water partition } \\
\text { coefficient }\left(\log K_{\text {ow }}\right)\end{array}$ \\
\hline Methyl & $99-76-3$ & 1.66 \\
Ethyl & $120-47-8$ & 2.19 \\
Propyl & $94-13-3$ & 2.71 \\
Butyl & $94-26-8$ & 3.24 \\
\hline
\end{tabular}

Parabens octanol/water partition coefficient $\left(K_{\mathrm{ow}}\right)$ [48]. mitochondrial membrane potential on isolated testis mitochondria in a side chain length- and concentration-dependent manner. In addition, parabens are potent inducers of the mitochondrial cyclosporin A-sensitive permeability transition in isolated mitochondria induced by calcium.

Despite all the controversy in published results, it has been unequivocally demonstrated that parabens exert a variety of effects on tissues and cell functions. As result of publications suggesting a link between parabens, breast cancer and testosterone levels, the Cosmetic Ingredient Review Expert Panel decided to reevaluate their safety [25].

\section{Economic uses of parabens}

Parabens are widely used as preservatives to inhibit microbial growth and extend shelf life of products in food, pharmaceuticals, cosmetics, sunscreens, skin-care products, conditioners, shampoos, soaps and deodorants. By far the most prevalent use of parabens has been in cosmetics. In fact, in 1984 it was estimated that parabens were used in 13,200 formulations [26] but a more recent survey of 215 cosmetic products found that parabens were used in $99 \%$ of leave-on products and $77 \%$ of rinse-off cosmetics. The total paraben content in paraben-positive cosmetics was found to be $0.01-0.87 \%$ [27]. Methyl- and propylparaben are the most commonly used preservatives in cosmetics [8] and the most frequently used preservative system is a combination of methyland propylparaben [28]. Parabens are allowed in concentrations of up to $1 \%$ in cosmetics. The European Community Directive allows the use of parabens with a maximum concentration for each one of $0.4 \%(\mathrm{w} / \mathrm{w})$ and total maximum concentration $0.8 \%$ $(\mathrm{w} / \mathrm{w})$. It is recognized that through cosmetics utilization, the frequency and duration of parabens application is often continuous and may extend over a period of years. However, many manufacturers are now reducing the use of parabens because of a growing evidence that parabens are not as safe as previously expected $[13,29]$.

\section{Environmental aspects}

Due to the wide use of parabens, they are continuously released into the aquatic media through domestic wastewater, and are therefore a growing concern in relation to their potential longterm effects on wildlife. Despite the weak endocrine disruptor activity shown by butylparaben, estrogenicity has been clearly demonstrated in a well-established fish test system [30]. Furthermore, butylparaben tested in juvenile rainbow trout (Oncorhynchus mykiss) for estrogenic activity was positive, inducing yolk protein synthesis (vitellogenin) [30]. Fish are very susceptible to parabens due to the lack of nonspecific esterase activity [31]. The threshold level after oral exposure in this system is in the same range as the doses reported to affect sperm production in male rodents [20-22]. Information concerning parabens in nature is scarce. In discharges from Swedish wastewaters a concentration of approximately $1 \mu \mathrm{g}$ paraben per liter (ethyl-, propyl- and benzylparaben) was found [32]. A study carried out in Portugal has shown that wastewater treatment plants are not prepared to efficiently eliminate parabens and other endocrine disruptors, since it was possible to detect methyl-ethyl-, propyl- and benzylparaben in sludge and in wastewater collected after treatment [33]. This could represent an environmental problem, given that sludge residues after dehydration are frequently used in agriculture to fertilize the fields. Canosa et al. [34] showed ou has shown that parabens react with free chlorine producing several halogenated by-products. Therefore, the use of parabens in personal care products and daily activities such as showering and bathing constitute a source of dermal exposition to 
paraben chlorinated by-products and no study has yet been carried out to evaluate potential health risks of this chlorinated parabens.

\section{Biochemical and toxicological data of parabens}

Animal studies have shown that parabens are rapidly absorbed, metabolized and excreted. Matthews et al. [35] reported that the use of the sodium salt of propylparaben is more efficiently absorbed by the gastrointestinal tract when compared to the free ester. Lakeram et al. [36] studied the effects of ethanol on parabens hydrolysis by using Caco-2 human intestinal cells and concluded that hydrolysis of parabens to $p$-hydroxybenzoic acid is markedly reduced by ethanol concentrations that can occur in the human intestine.

Metabolism of parabens was studied by treating rats with $100 \mathrm{mg}$ of methyl- or propylparaben orally. After oral administration in rats, parabens are absorbed from the gastrointestinal tract and quickly hydrolyzed, to different metabolites, by esterases [37].

Parabens can also be rapidly absorbed by the intact skin [38] and hydrolyzed to $p$-hydroxybenzoic acid and their respective side chains [39]; however studies addressing percutaneous absorption of parabens performed in animals and in vitro studies have shown that butylparaben exhibits low penetration, retention in the epidermis and/or hydrolysis in the skin [4]. In a study performed with human skin, it was estimated that butylparaben can be absorbed in an amount of up to $576 \mathrm{mg}$ after treating the whole body skin surface of $1.8 \mathrm{~m}^{2}$ with saturated solution of butylparaben [40]. Maximum fluxes and permeability constants of paraben were measured from different vehicles representing hydrophilic and lipophilic phases, and from different types of common commercial cosmetic emulsions, each containing a known quantity of a single member of the paraben series. The fluxes were shown not to be significantly dependent on the emulsions characteristics, since the highest value were always obtained for methylparaben and decreased with increasing lipophilic character of the preservative [41]. In pharmaceutical products, cyclodextrins act as drug carriers, improving dissolution and enhancing absorption of drugs. Chan et al. [42] studied the interaction of parabens with $\beta$-cyclodextrin and the results showed methylparaben with the higher extent of interaction, concluding that the extent of interaction was influenced by the hydrophobicity and steric energy of the parabens.

In a series of studies performed with parabens it was suggested that parabens could induce cell hemolysis and biochemical changes in mice liver and kidney by inducing oxidative stress and lipid peroxidation [43]. Allergic contact dermatitis from paraben is low, ranging from 0 to $4.2 \%$ [26]. However, the percentage can be significantly increased in patients with chronic leg ulcers [44].

Animal studies have shown that butylparaben exposure is adverse to male reproduction $[20,21,45]$. This will be discussed in one of the following sections.

\section{Human infertility caused by xenobiotics}

Approximately $15 \%$ of couples have infertility problems [46]. However, and despite the increasing knowledge on the physiological basis of infertility, the reasons for this problem remain undiagnosed in a number of cases, a condition known as idiopathic infertility. Due to unrestricted human activity, widespread environmental pollutants may be at least partially responsible for some of these cases. In fact, epidemiologic evidence supports an association between exposure to environmental toxicants and reproductive outcome, including in humans. Some xenobiotics, such as persistent organic pollutants (POPs), DES (diethylstilbestrol) or parabens act like endocrine disruptors, exogenous chemicals that often interfere with the normal hypothalamo-pituitary-gonadal axis, mimicking hormones, blocking hormonal action or triggering inap- propriate hormone activity. Since they tend to mimic female hormones, these compounds especially affect male reproductive function [47]. POPs such as PCBs (polychlorinated biphenyls), DDT (dichloro diphenyl trichloroethane), PCDDs (polychlorinated dibenzo-p-dioxins) and PCDFs (polychlorinated dibenzofurans) may not only impair sperm motility, but also adversely affect sperm concentration, semen volume and sperm morphology [48-52], although contradictory results exist [53,54]. Dioxins may also reduce serum and testicular testosterone levels [55] and increase gonadotropin concentrations [56], while also decreasing sperm motility [57]. Commonly used industrial chemicals, such as phthalates, are also associated with male reproductive toxicity in humans $[58,59]$. Specifically, dose-response relations between monobutyl phthalate (MBP), sperm motility and sperm concentration and also a dose-response relation between monobenzyl phthalate (MBzP) and sperm concentration were detected. Evidence for an association between monomethyl phthalate (MMP) with poor sperm morphology was also described [59]. More worrisome is the recent discovery by Swan et al. [60] that maternal beef consumption during pregnancy may alter testicular development in utero and adversely affect reproductive capacity due to the possible presence of xenobiotics in beef, possibly related to changes in animal growth procedures in the previous generation. In accordance, men whose mothers had been treated with DES to prevent miscarriages, show an increase in the incidence of cryptorchidism and hypospadias, as well as diminished sperm quality [61].

Additionally, heavy metals such as lead and cadmium may also cause an adverse effect on male reproductive functions [62-68]. The presence of heavy metals in semen was also associated with poor chromatin condensation [69], lower pregnancy rates and birth defects [70]. Furthermore, a reduction in testosterone synthesis and an increase in LH and FSH levels without a clear indication of disturbance of the hypothalamic-pituitary-testicular axis have been described [71].

Although there is increasing concern regarding the effects of parabens, namely, as mentioned previously, a possible role on the increased incidence of breast cancer [18], little data exists on their effects regarding human sperm, although a number of studies with animal models were performed. Rodent exposure to butylparaben $[20,21]$ and propylparaben [22] adversely affected testosterone synthesis and male reproductive function. On the other hand, a recent study performed by the same author exhibited contrary results for methyl- and ethylparaben [72]. Although parabens have weak estrogenic activity, confirmed by positive uterotrophic assays $[11,15,17,73,74]$, these findings are in agreement with studies that indicate that methyl and ethyl esters have less potent in vitro and in vivo estrogenic activity than either propylparaben or the most potent form, butylparaben $[73,74]$. In fact, another study performed in fish demonstrated that ethylparaben is approximately sixty times weaker than propyl- and butylparaben [75]. Finally, a study concerning the effects of maternal exposure to butylparaben during gestation and lactation periods demonstrated that this exposure may adversely affect reproductive organ development of male F1 progeny [47]. In fact, the proportion of pups born alive and the percentage of pups surviving to weaning were significantly decreased following exposure. Also, and more importantly, male reproductive organ weights (testes, seminal vesicles and prostate glands), sperm counts and sperm motility were adversely affected as well as the number of round and elongated spermatids at stage VII of the seminiferous tubule. Vaginal opening also occurred earlier in female offspring, compared with the control group [47].

An issue of great concern is the transgenerational effects of endocrine-disrupting agents, possibly mediated by imprinting. DNA in primordial germ cells is demethylated and remethylated in a sex-specific manner during gonadal sex determination [76], and 
DNA methylation controls gene expression [77]. Methoxychlor, a DDT substitute, and vinclozolin, a fungicide used in the wine industry, were both shown to modify the spermatogenic capacity of male germ cells and sperm viability through DNA methylation. Thus, reduced fertility and sperm development in rat testis of offspring exposed during pregnancy was demonstrated in this system. More importantly, this phenotype was transmitted, with no additional exposure, through the male germ line to at least the F4 generation [78].

\section{Animal and human data on paraben effects on reproduction}

A study carried out by Fisher et al. [79] demonstrated that male neonatal rats injected with butylparaben at $2 \mathrm{mg} / \mathrm{kg}$ on postnatal days 2-18 showed no detectable effects on any reproductive parameter. On the contrary, Oishi reported no treatment-related effects of propylparaben on reproductive organ weights [22] but decreased epididymes and seminal vesicles weights after dietary butylparaben intake were recorded [20]. Furthermore, a significant decline of caudal epididymal sperm reserves was described for methyl- and butylparaben consumption [20,22]. Moreover, sperm concentration decreased in a dose-dependent manner and the same was observed with daily sperm production (DSP) and efficiency of sperm production in testes (DSP/g testes). Surprisingly, a dose-dependent decrease in serum testosterone concentration was also reported in rodents fed with methyl- or butylparaben [20-22]. An inverse relationship was found between butylparaben concentration and both round and elongated spermatid counts in stages VII-VIII of the seminiferous tubule cycle in mice. Also, elongated spermatid counts were significantly lower in all treated groups [21]. Nevertheless, the same author found that neither male reproductive functions nor serum hormone concentrations including testosterone, LH and FSH were affected by methyl- and ethylparaben at a dose level of about $1000 \mathrm{mg} / \mathrm{kg}$ bw/day [72]. These results are in agreement with previous data that observed no adverse histopathological effects on male reproductive organs in rodents fed with $0.6-10 \%, 2 \%$ and $0.15-0.6 \%$ butylparaben for 6 , 8 and 102 weeks, respectively [35,80]. However, these studies did not determine sperm parameters or reproductive hormone levels. A recent study carried out by Hoberman et al. [81] tried to reproduce the same conditions as reported by Oishi $[20,72]$. Nevertheless, male Wistar rats orally exposed to $0,100,1000$ or $10,000 \mathrm{ppm}$ methyl- or butylparaben for 8 weeks did not present any significant changes on reproductive organ weights, sperm motility, sperm count and DSP. Additionally, no modifications in hormone levels were observed in butylparaben-treated animals. Therefore, the study suggests that the rapid metabolism of parabens by esterases may be the reason for why these compunds do not induce in vivo effects when administered by oral route. A toxicological evaluation of butylparaben given by oral administration to Sprague-Dawley rats showed no differences versus the control group in any of the developmental parameters including embryo/foetal viability, foetal weight, malformations or variations. The maternal NOAEL (noobserved-adverse-effect level) for butylparaben was established at $100 \mathrm{mg} / \mathrm{kg}$ bw/day. It was further concluded that butylparaben does not have the potential to produce developmental toxicity in the Sprague-Dawley rat at oral dosages up to $1000 \mathrm{mg} / \mathrm{kg}$ bw/day [82].

Parabens are structurally similar to some environmental estrogen disruptors and function as sulfotransferase inhibitors [83], therefore it is possible that parabens interact with other processes in the skin estrogen cycle. In fact, a study performed by Prusakiewicz et al. [7] showed that parabens inhibit estrogen and estradiol sulfation by inhibiting sulfotransferase activity in skin, suggesting that chronic topical application of parabens may lead
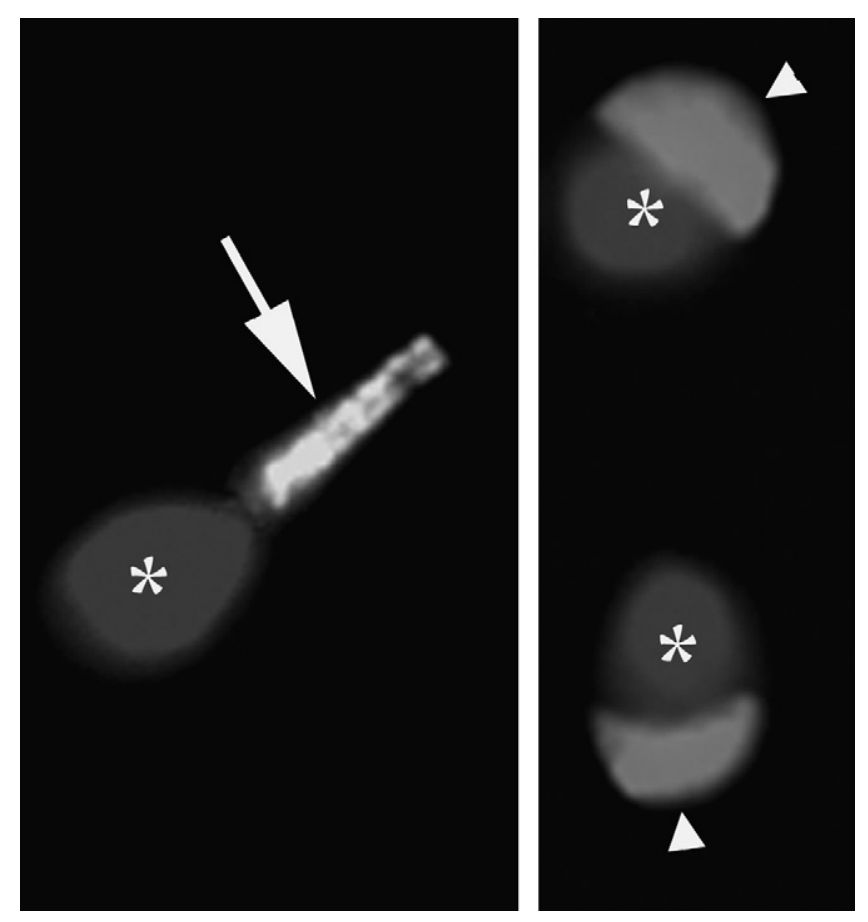

Fig. 2. Possible targets of paraben action on human spermatozoa. Parabens may interfere with sperm mitochondria (either during spermatogenesis on following sperm maturation), organized in the sperm midpiece (arrow) and also with the acrosome, a cap-like secretory vesicle on the sperm head containing hydrolytic enzymes essential for sperm-oocyte interactions (arrowheads). As is the case with other xenobiotics, sperm nuclear DNA (asterisks) may also be affected by paraben exposure. To obtain these images mitochondria were labeled with the organellespecific dye Mito Tracker Green, the acrosome with the fluorescent lectin PSA-FITC and DNA with the DNA dye DAPI, and the sperm observed under fluorescence.

to prolonged estrogenic effects in the skin. In a number of in vitro studies, parabens were able to bind the estrogen receptor, activating genes controlled by these receptors, and stimulating cell growth and increasing the level of immune reactive estrogen receptor protein $[7,13,16]$. Subcutaneous administration of butylparaben has also been shown to increase uterine weight in vivo in both immature rats and mice and in adult ovariectomised mice, hence confirming its estrogenic activity $[4,73]$. The issue of paraben effects on human reproductive toxicity was addressed by Glander et al. [84], who studied primary microbiological contamination in human ejaculates, and also secondary contamination after cryopreservation using methylparaben. These authors found that not only methylparaben reduced microbiological contamination of the cryoprotective medium, but also decreased human sperm motility [84]. Additionally, another study regarding in vitro spermicidal activity of methyl-, ethyl-, propyl- and butylparaben in human subjects found that, in fact, these parabens are effective spermicides [85]. Later on, another report showed that butylparaben exerts an inhibitory effect on the acrosomal enzyme acrosin, and impairs sperm membrane function, indicating that it can potentially be used as a contraceptive [86], and suggesting another target for paraben action on sperm (Fig. 2). However, a severe allergic reaction in a man that used a condom with retarding cream containing a mixture of benzocaine and paraben was reported [87]. Although effects of parabens seem to adversely affect male reproduction, further studies are required to better understand toxicity and also to establish reliable threshold values that may accurately indicate when reproduction may be seriously compromised. So far, and to our knowledge, no reports have been published regarding the effects of parabens on female gametes. 


\section{Mitochondrial toxicology of parabens}

Due to the critical role of mitochondria on cell energetics, it is wise to consider that the negative interaction of several molecules with mitochondria affects cell functions. Mitochondria are the recognized cell powerhouses mainly due to the production of the majority of the ATP used by cell processes. Although this energyproducing role would per se be enough to justify the importance of studying drug-mitochondria interactions, there are other mitochondrial functions that are very important in the context of drug-induced mitochondrial and tissue dysfunction. The role of mitochondria as a crossroad in several cell death pathways has been established $[88,89]$. The mitochondrial permeability transition (MPT) is triggered by several agents known to cause cell death, one example being the pro-oxidant anti-neoplastic agent doxorubicin [90,91]. Mitochondria are also responsible for participating in the regulation of cytosolic calcium homeostasis [92]. Several toxicants can interfere with mitochondrial control of cytosolic calcium, which can be critical in tissues where constant calcium spikes signal cell responses [93]. Also, many of the mitochondrial toxicants interact with the core of the ATP generation processes, the mitochondrial respiratory chain and phosphorylative system [94-96], as well as with DNA or protein regulation [97,98]. Although tissues with higher needs of mitochondrial-produced ATP will be the mostly affected by drug-induced mitochondrial dysfunction, tissues with apparent low energy demand can also be affected. One of such cases is the toxicity of several agents on testis mitochondria. Agents such as doxorubicin [99], cadmium [100] or anti-HIV nucleoside pharmaceuticals [101] are recognized mitochondrial disruptors in the testis, although the literature is not extensive regarding the precise mechanism of drug-induced mitochondrial dysfunction. Fig. 3 exemplifies possible sites for drug-induced mitochondrial dysfunction, including the respiratory chain and the MPT.
The mitochondrial toxicity of parabens is not a widespread topic in the literature. It has been previously described that parabens cause a concentration- and time-dependent cell death of cultured hepatocytes [23] with such toxicity correlated with defective mitochondrial function. The same work not only established a correlation between paraben structure and activity but also identified the mitochondrial respiratory chain and phosphorylation system as a target for the different parabens used. It was demonstrated that butyl- and isobutylparaben were more toxic than propyl- and isopropylparaben, and ethyl- methylparaben and p-hydroxybenzoic acid were less toxic than propylparaben, when considering mitochondria as the site for the toxic effect [23]. Later, it was pointed out that the MPT pore is involved in the toxicity of different parabens in hepatocytes and isolated liver mitochondria [102]. The results are extremely important as they are first to demonstrate that the paraben-induced uncoupling and decrease of ATP synthesis is associated with MPT induction.

Due to the important role of mitochondria in testis metabolism, it is logical to assume that parabens may also interfere with mitochondrial energetics and thus disturb sperm function. Although no data exist on direct effects of parabens on testis mitochondria, it seems possible that tissue accumulation of such compounds would lead to toxicological relevant concentrations that would disturb mitochondrial bioenergetics. In fact, preliminary results from our laboratory indicate that several parabens present direct toxicity on isolated testis mitochondria at low concentrations (Peixoto et al., in preparation). Although some organelle-dependent differences may exist, the similar structure, function and energy-production mechanism of both liver and testis mitochondria are very likely to be affected in the same range of paraben concentrations, raising an important question: what is the relevance of paraben-mitochondria interactions in male reproductive problems associated with prolonged exposure to those compounds? In fact, several compounds

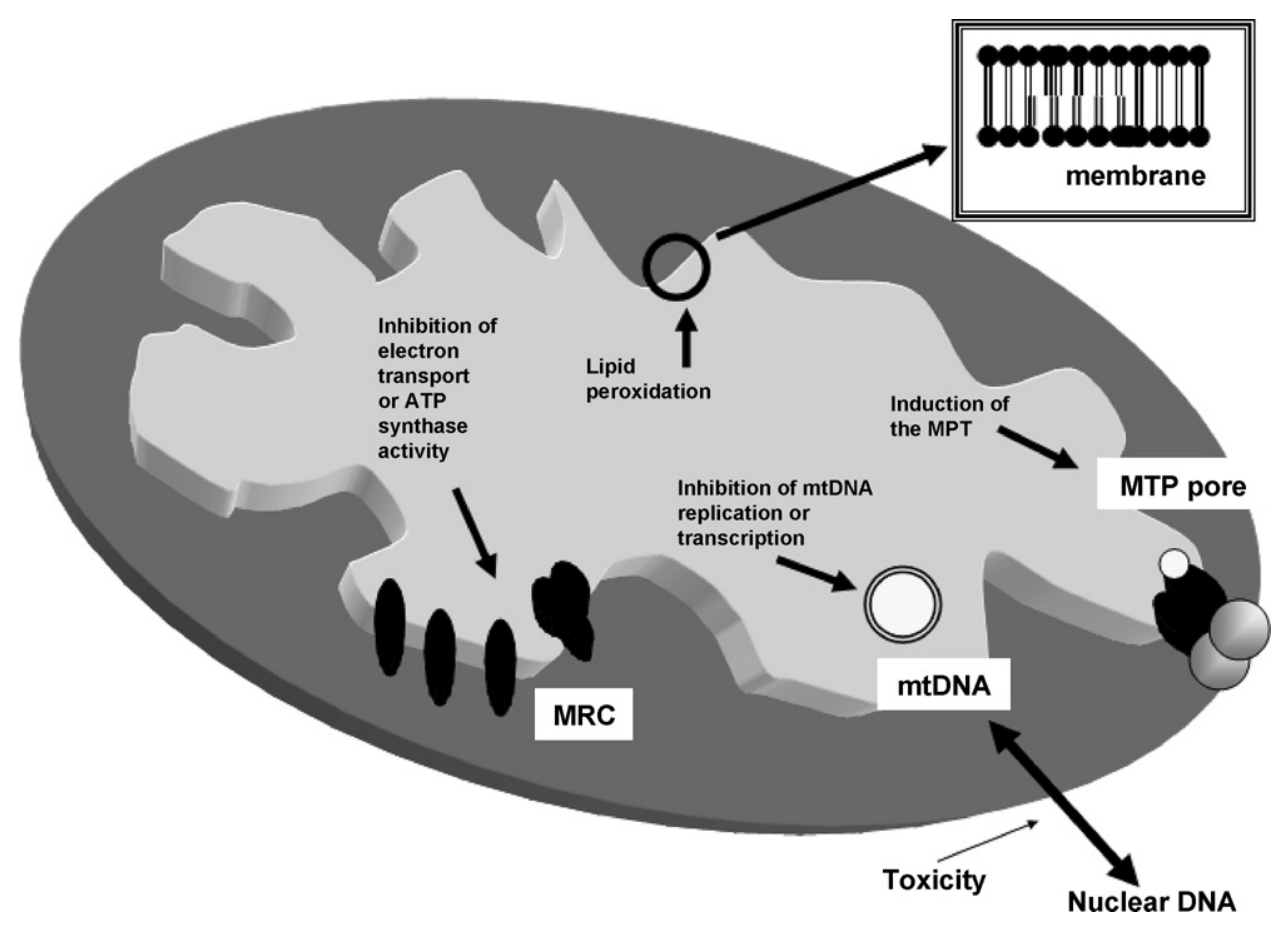

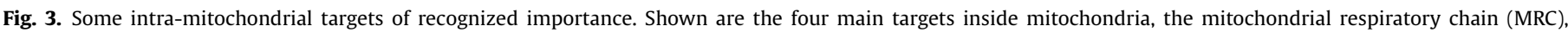

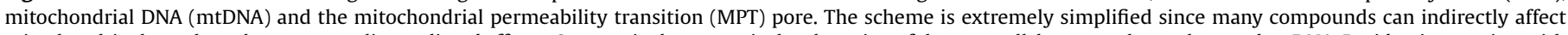

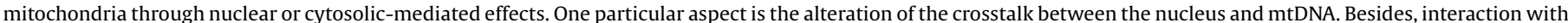

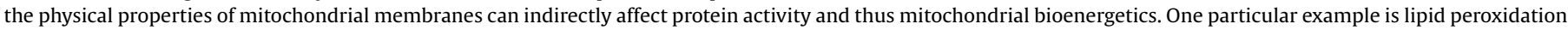

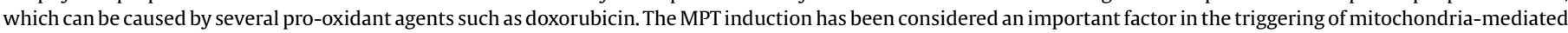
cell death. 
known to cause decreased reproductive potential in males are also known to interfere with testis mitochondrial function. The list of compounds includes dioxins [103] and phthalic acid esters [104]. Respiratory function of testicular mitochondria appears particularly susceptible to xenobiotic actions, which can contribute to a decrease in mitochondrially produced ATP and even to predispose cells to undergo mitochondria-mediated cell death.

It is very likely that the next years will see the appearance of several papers exploring the effect of different parabens on testis mitochondrial function, and possibly also on what may happen in mature male gametes. The relation between inhibition of testis mitochondrial function and male reproductive problems induced by parabens will be very important in the context of the toxicity assessment of commonly used parabens.

\section{Conflict of interest}

None.

\section{References}

[1] Neidig CP, Burrell $\mathrm{H}$. The esters of $p$-hydroxybenzoic acids as preservatives. Drug Cosmetic Indust 1944;54:408-10.

[2] Han J, Washington C. Partition of antimicrobial additives in an intravenous emulsion and their effect on emulsion physical stability. Int J Pharm 2005;288:263-71.

[3] Dal Pozzo A, Pastori N. Percutaneous absorption of parabens from cosmetic formulations. Int J Cosmetic Sci 1996;18:57-66.

[4] Soni MG, Carabin IG, Burdock GA. Safety assessment of esters of $p$ hydroxybenzoic acid (parabens). Food Chem Toxicol 2005;43:985-1015.

[5] Fujita F, Moriyama T, Higashi T, Shima A, Tominaga M. Methyl phydroxybenzoate causes pain sensation through activation of TRPA1 channels. Br J Pharmacol 2007; 151:153-60.

[6] Ishiwatari S, Suzuki T, Hitomi T, Yoshino T, Matsukuma S, Tsuji T. Effects of methyl paraben on skin keratinocytes. J Appl Toxicol 2007;27:1-9.

[7] Prusakiewicz JJ, Harville HM, Zhang Y, Ackermann C, Voorman RL. Parabens inhibit human skin estrogen sulfotransferase activity: possible link to paraben estrogenic effects. Toxicology 2007;232(3):248-56.

[8] Soni MG, Burdock GA, Taylor SL, Greenberg NA. Safety assessment of propyl paraben: a review of the published literature. Food Chem Toxicol 2001;39:513-32.

[9] Golden R, Gandy J, Vollmer G. A review of the endocrine activity of parabens and implications for potential risks to human health. Crit Rev Toxicol 2005;35:435-58.

[10] Harvey PW, Everett DJ. Regulation of endocrine-disrupting chemicals: critical overview and deficiencies in toxicology and risk assessment for human health. Best Pract Res Cl En 2006;20:145-65.

[11] Koda T, Umezu T, Kamata R, Morohoshi K, Ohta T, Morita M. Uterotrophic effects of benzophenone derivatives and a $p$-hydroxybenzoate used in ultraviolet screens. Environ Res 2005;98:40-5.

[12] Harvey PW. Parabens, oestrogenicity, underarm cosmetics and breast cancer: a perspective on a hypothesis. J Appl Toxicol 2003;23:285-8.

[13] Pugazhendhi D, Pope GS, Darbre PD. Oestrogenic activity of $p$-hydroxybenzoic acid (common metabolite of paraben esters) and methylparaben in human breast cancer cell lines. J Appl Toxicol 2005;25:301-9.

[14] McGrath KG. An earlier age of breast cancer diagnosis related to more frequent use of antiperspirants/deodorants and underarm shaving. Eur J Cancer Prev 2003;12:479-85.

[15] Okubo T, Yokoyama Y, Kano K, Kano I. ER-dependent estrogenic activity of parabens assessed by proliferation of human breast cancer MCF-7 cells and expression of ERalpha and PR. Food Chem Toxicol 2001;39:1225-32.

[16] Byford JR, Shaw LE, Drew MG, Pope GS, Sauer MJ, Darbre PD. Oestrogenic activity of parabens in MCF7 human breast cancer cells. J Steroid Biochem Mol Biol 2002;80:49-60.

[17] Darbre PD, Byford JR, Shaw LE, Horton RA, Pope GS, Sauer MJ. Oestrogenic activity of isobutylparaben in vitro and in vivo. J Appl Toxicol 2002;22:219-26.

[18] Darbre PD, Byford JR, Shaw LE, Hall S, Coldham NG, Pope GS, et al. Oestrogenic activity of benzylparaben. J Appl Toxicol 2003;23:43-51.

[19] Mirick DK, Davis S, Thomas DB. Antiperspirant use and the risk of breast cancer. J Natl Cancer Inst 2002;94:1578-80.

[20] Oishi S. Effects of butylparaben on the male reproductive system in rats. Toxicol Ind Health 2001;17:31-9.

[21] Oishi S. Effects of butyl paraben on the male reproductive system in mice. Arch Toxicol 2002;76:423-9.

[22] Oishi S. Effects of propyl paraben on the male reproductive system. Food Chem Toxicol 2002;40:1807-13.

[23] Nakagawa Y, Moldeus P. Mechanism of p-hydroxybenzoate ester-induced mitochondrial dysfunction and cytotoxicity in isolated rat hepatocytes. Biochem Pharmacol 1998;55:1907-14.
[24] Martins F, Margarida A, Oliveira MM, Oliveira PJ, Francisco P, Peixoto FP. Toxicity of parabens in testis mitochondria: a possible role on male infertility. Biochimica et Biophysica Acta-Bioenergetics 2008;1777:S60-1.

[25] Bergfeld WF, Belsito DV, Marks Jr JG, Andersen FA. Safety of ingredients used in cosmetics. J Am Acad Dermatol 2005;52:125-32.

[26] Elder RL. Final report on the safety assessment of methylparaben, ethylparaben, propylparaben, and butylparaben. J Am Coll Toxicol 1984;3:147-209.

[27] Rastogi SC, Schouten A, de Kruijf N, Weijland JW. Contents of methyl-, ethyl-, propyl-, butyl- and benzylparaben in cosmetic products. Contact Dermatitis 1995;32:28-30.

[28] Jackson EM. Moisturizers of Today. J Toxicol Cutaneous Ocul Toxicol 1992;11:173-84.

[29] Darbre PD, Aljarrah A, Miller WR, Coldham NG, Sauer MJ, Pope GS. Concentrations of parabens in human breast tumours. J Appl Toxicol 2004;24: 5-13.

[30] Alslev B, Korsgaard B, Bjerregaard P. Estrogenicity of butylparaben in rainbow trout Oncorhynchus mykiss exposed via food and water. Aquat Toxicol 2005;72:295-304

[31] Li SN, Fan DF. Activity of esterases from different tissues of freshwater fish and responses of their isoenzymes to inhibitors. J Toxicol Environ Health 1997;51:149-57.

[32] Paxeus N. Organic pollutants in the effluents of large wastewater treatment plants in Sweden. Water Res 1996;30:1115-22.

[33] Leite AM. Estudo de desreguladores endócrinos numa Estação de Tratamento de Águas Residuais (Master thesis). Vila Real: University of Trás-os-Montes and Alto Douro; 2006.

[34] Canosa P, Rodriguez I, Rubi E, Negreira N, Cela R. Formation of halogenated by-products of parabens in chlorinated water. Anal Chim Acta 2006;575: 106-13.

[35] Matthews C, Davidson J, Bauer E, Morrison JL, Richardson AP. pHydroxybenzoic acid esters as preservatives. II. Acute and chronic toxicity in dogs, rats, and mice. J Am Pharm Assoc Am Pharm Assoc (Baltim) 1956;45: 260-7.

[36] Lakeram M, Paine AJ, Lockley DJ, Sanders DJ, Pendlington R, Forbes B. Trans esterification of $p$-hydroxybenzoate esters (parabens) by human intestinal (Caco-2) cells. Xenobiotica 2006;36:739-49.

[37] Derache R, Gourdon J. Metabolism of a food preservative: parahydroxybenzoic acid and its esters. Food Cosmetic Toxicol 1963;1:189-95.

[38] Akomeah F, Nazir T, Martin GP, Brown MB. Effect of heat on the percutaneous absorption and skin retention of three model penetrants. Eur J Pharm Sci 2004;21:337-45

[39] Lobemeier C, Tschoetschel C, Westie S, Heymann E. Hydrolysis of parabenes by extracts from differing layers of human skin. Biol Chem 1996;377:647-51.

[40] Hagedorn-Leweke U, Lippold BC. Absorption of sunscreens and other compounds through human skin in vivo: derivation of a method to predict maximum fluxes. Pharm Res 1995;12:1354-60.

[41] Kitagawa S, Li H, Sato S. Skin permeation of parabens in excised guinea pig dorsal skin, its modification by penetration enhancers and their relationship with n-octanol/water partition coefficients. Chem Pharm Bull (Tokyo) 1997:45:1354-7.

[42] Chan LW, Kurup TR, Muthaiah A, Thenmozhiyal JC. Interaction of $p$-hydroxybenzoic esters with beta-cyclodextrin. Int J Pharm 2000;195(1/2):71-9.

[43] Verma RJ, Asnani V. Ginger extract ameliorates paraben induced biochemical changes in liver and kidney of mice. Acta Pol Pharm 2007;64:217-20.

[44] Davis Kag L, Wexler DM. Paraben sensitivity. Can J Dermatol 1992;4:198

[45] Kang KS, Che JH, Ryu DY, Kim TW, Li GX, Lee YS. Decreased sperm number and motile activity on the F1 offspring maternally exposed to buty p-hydroxybenzoic acid (butyl paraben). J Vet Med Sci 2002;64:227-35.

[46] Oehninger S. Strategies for the infertile man. Semin Reprod Med 2001;19: 231-7.

[47] Dhooge W, van Larebeke N, Koppen G, Nelen V, Schoeters G, Vlietinck R, et al. Serum dioxin-like activity is associated with reproductive parameters in young men from the general Flemish population. Environ Health Perspect 2006:114:1670-6.

[48] Dallinga JW, Moonen EJ, Dumoulin JC, Evers JL, Geraedts JP, Kleinjans JC. Decreased human semen quality and organochlorine compounds in blood. Hum Reprod 2002;17:1973-9.

[49] Richthoff J, Rylander L, Jonsson BA, Akesson H, Hagmar L, Nilsson-Ehle P, et al. Serum levels of $2,2^{\prime}, 4,4^{\prime}, 5,5^{\prime}$-hexachlorobiphenyl (CB-153) in relation to markers of reproductive function in young males from the general Swedish population. Environ Health Perspect 2003;11:409-13.

[50] Rignell-Hydbom A, Rylander L, Giwercman A, Jonsson BA, Lindh C, Eleuteri P et al. Exposure to PCBs and $p, p^{\prime}$-DDE and human sperm chromatin integrity. Environ Health Perspect 2005;113:175-9.

[51] Tiido T, Rignell-Hydbom A, Jonsson BA, Giwercman YL, Pedersen HS, Wojtyniak B, et al. Impact of PCB and $p, p^{\prime}$-DDE contaminants on human sperm $Y: X$ chromosome ratio: studies in three European populations and the Inuit population in Greenland. Environ Health Perspect 2006;114:718-24.

[52] Guo YL, Hsu PC, Hsu CC, Lambert GH. Semen quality after prenatal exposure to polychlorinated biphenyls and dibenzofurans. Lancet 2000;356: 1240-1.

[53] Dalvie MA, Myers JE, Thompson ML, Robins TG, Dyer S, Riebow J, et al. The long-term effects of DDT exposure on semen, fertility, and sexual function of malaria vector-control workers in Limpopo Province, South Africa. Environ Res 2004;96:1-8. 
[54] Weiss JM, Bauer O, Bluthgen A, Ludwig AK, Vollersen E, Kaisi M, et al. Distribution of persistent organochlorine contaminants in infertile patients from Tanzania and Germany. J Assist Reprod Genet 2006;23:393-9.

[55] Mebus CA, Reddy VR, Piper WN. Depression of rat testicular 17-hydroxylase and 17,20-lyase after administration of 2,3,7,8-tetrachlorodibenzo-p-dioxin (TCDD). Biochem Pharmacol 1987;36:727-31.

[56] Egeland GM, Sweeney MH, Fingerhut MA, Wille KK, Schnorr TM, Halperin WE. Total serum testosterone and gonadotropins in workers exposed to dioxin. Am J Epidemiol 1994;139:272-81.

[57] Comhaire FH, Mahmoud AM, Schoonjans F. Sperm quality, birth rates and the environment in Flanders (Belgium). Reprod Toxicol 2007;23:133-7.

[58] WHO. WHO laboratory manual for the examination of human semen and sperm-cervical mucus interaction, Cambridge; 1999.

[59] Duty SM, Silva MJ, Barr DB, Brock JW, Ryan L, Chen Z, et al. Phthalate exposure and human semen parameters. Epidemiology 2003;14:269-77.

[60] Swan SH, Liu F, Overstreet JW, Brazil C, Skakkebaek NE. Semen quality of fertile US males in relation to their mothers' beef consumption during pregnancy. Hum Reprod 2007;22:1497-502.

[61] Sharpe RM, Skakkebaek NE. Are oestrogens involved in falling sperm counts and disorders of the male reproductive tract? Lancet 1993;341:1392-5.

[62] Oliveira H, Loureiro J, Filipe L, Santos C, Ramalho-Santos J, Sousa M, et al. Flow cytometry evaluation of lead and cadmium effects on mouse spermatogenesis. Reprod Toxicol 2006;22:529-35.

[63] Lerda D. Study of sperm characteristics in persons occupationally exposed to lead. Am J Ind Med 1992;22:567-71.

[64] Xuezhi J, Youxin L, Yilan W. Studies of lead exposure on reproductive system: a review of work in China. Biomed Environ Sci 1992;5:266-75.

[65] Robins TG, Bornman MS, Ehrlich RI, Cantrell AC, Pienaar E, Vallabh J, et al. Semen quality and fertility of men employed in a South African lead acid battery plant. Am J Ind Med 1997;32:369-76.

[66] Telisman S, Cvitkovic P, Jurasovic J, Pizent A, Gavella M, Rocic B. Semen quality and reproductive endocrine function in relation to biomarkers of lead, cadmium, zinc, and copper in men. Environ Health Perspect 2000;108:45-53.

[67] Braunstein GD, Dahlgren J, Loriaux DL. Hypogonadism in chronically leadpoisoned men. Infertility 1978;1(1):33-51.

[68] Xu B, Chia SE, Tsakok M, Ong CN. Trace elements in blood and seminal plasma and their relationship to sperm quality. Reprod Toxicol 1993;7:613-8.

[69] Hernandez-Ochoa I, Garcia-Vargas G, Lopez-Carrillo L, Rubio-Andrade M, Moran-Martinez J, Cebrian ME, et al. Low lead environmental exposure alters semen quality and sperm chromatin condensation in northern Mexico. Reprod Toxicol 2005;20:221-8.

[70] Sallmen M, Lindbohm ML, Anttila A, Taskinen H, Hemminki K. Paternal occupational lead exposure and congenital malformations. J Epidemiol Community Health 1992;46:519-22.

[71] Gennart JP, Buchet JP, Roels H, Ghyselen P, Ceulemans E, Lauwerys R. Fertility of male workers exposed to cadmium, lead, or manganese. Am J Epidemiol 1992;135:1208-19.

[72] Oishi S. Lack of spermatotoxic effects of methyl and ethyl esters of $p$ hydroxybenzoic acid in rats. Food Chem Toxicol 2004;42:1845-9.

[73] Routledge EJ, Parker J, Odum J, Ashby J, Sumpter JP. Some alkyl hydroxy benzoate preservatives (parabens) are estrogenic. Toxicol Appl Pharm 1998;153 (1):12-9.

[74] Blair RM, Fang H, Branham WS, Hass BS, Dial SL, Moland CL, et al. The estrogen receptor relative binding affinities of 188 natural and xenochemicals: structural diversity of ligands. Toxicol Sci 2000;54:138-53.

[75] Pedersen KL, Pedersen SN, Christiansen LB, Korsgaard B, Bjerregaard P. The preservatives ethyl-, propyl- and butylparaben are oestrogenic in an in vivo fish assay. Pharmacol Toxicol 2000;86:110-3.

[76] Reik W, Dean W, Walter J. Epigenetic reprogramming in mammalian development. Science 2001;293:1089-93.

[77] Razin A, Kantor B. DNA methylation in epigenetic control of gene expression. Prog Mol Subcell Biol 2005;38:151-67.

[78] Anway MD, Cupp AS, Uzumcu M, Skinner MK. Epigenetic transgenerational actions of endocrine disruptors and male fertility. Science 2005;308:1466-9.

[79] Fisher JS, Turner KJ, Brown D, Sharpe RM. Effect of neonatal exposure to estrogenic compounds on development of the excurrent ducts of the rat testis through puberty to adulthood. Environ Health Persp 1999;107:397-405.

[80] Inai K, Aoki Y, Akamizu H, Eto R, Nishida T, Tukuoka S. Tumorigenicity study of butyl and isobutyl $p$-hydroxybenzoates administered orally to mice. Food Chem Toxicol 1985;23:575-8.
[81] Hoberman AL, Schreur DK, Leazer T, Daston GP, Carthew P, Re T, et al. Lack of effect of butylparaben and methylparaben on the reproductive system in male rats. Birth Def Res (Part B) 2008;83:123-33.

[82] Daston GP. Developmental toxicity evaluation of butylparaben in Sprague-Dawley rats. Birth Defects Res B Dev Reprod Toxicol 2004;71: 296-302.

[83] Kester MH, Bulduk S, van Toor H, Tibboel D, Meinl W, Glatt H, et al. Potent inhibition of estrogen sulfotransferase by hydroxylated metabolites of polyhalogenated aromatic hydrocarbons reveals alternative mechanism for estrogenic activity of endocrine disrupters. J Clin Endocrinol Metab 2002;87:1142-50.

[84] Glander HG, Rytter M, Schonborn C. Studies on the mycotic and bacterial risk of contamination and the use of nipagin in the artificial insemination of cryosperm. Zentralbl Gynakol 1984;106:573-84.

[85] Song BL, Li HY, Peng DR. In vitro spermicidal activity of parabens against human-spermatozoa. Contraception 1989;39:331-5.

[86] Song BL, Peng DR, Li HY, Zhang GH, Zhang J, Li KL, et al. Evaluation of the effect of butyl $p$-hydroxybenzoate on the proteolytic activity and membrane function of human spermatozoa. J Reprod Fertil 1991;91:435-40.

[87] Foti C, Bonamonte D, Antelmi A, Conserva A, Angelini G. Allergic contact dermatitis to condoms: description of a clinical case and analytical review of current literature. Immunopharm Immunol 2004;26(3):481-5.

[88] Orrenius S, Gogvadze V, Zhivotovsky B. Mitochondrial oxidative stress: implications for cell death. Annu Rev Pharmacol Toxicol 2007;47:143-83.

[89] Antignani A, Youle RJ. How do Bax and Bak lead to permeabilization of the outer mitochondrial membrane? Curr Opin Cell Biol 2006;18:685-9.

[90] Oliveira PJ, Bjork JA, Santos MS, Leino RL, Froberg MK, Moreno AJ, et al. Carvedilol-mediated antioxidant protection against doxorubicin-induced cardiac mitochondrial toxicity. Toxicol Appl Pharmacol 2004;200:159-68.

[91] Kroemer G, Galluzzi L, Brenner C. Mitochondrial membrane permeabilization in cell death. Physiol Rev 2007;87:99-163.

[92] Alonso MT, Villalobos C, Chamero P, Alvarez J, Garcia-Sancho J. Calcium microdomains in mitochondria and nucleus. Cell Calcium 2006;40: $513-25$.

[93] Hajnoczky G, Csordas G, Das S, Garcia-Perez C, Saotome M, Sinha Roy $\mathrm{S}$, et al. Mitochondrial calcium signalling and cell death: approaches for assessing the role of mitochondrial $\mathrm{Ca}^{2+}$ uptake in apoptosis. Cell Calcium 2006;40(5/6):553-60.

[94] Peixoto F. Comparative effects of the Roundup and glyphosate on mitochondrial oxidative phosphorylation. Chemosphere 2005;61:1115-22.

[95] Irwin W, Fontaine E, Agnolucci L, Penzo D, Betto R, Bortolotto S, et al. Bupivacaine myotoxicity is mediated by mitochondria. J Biol Chem 2002;277: 12221-7.

[96] Scatena R, Bottoni P, Botta G, Martorana GE, Giardina B. The role of mitochondria in pharmacotoxicology: a reevaluation of an old, newly emerging topic. Am J Physiol Cell Physiol 2007;293:C12-21.

[97] Saitoh A, Fenton T, Alvero C, Fletcher CV, Spector SA. Impact of nucleoside reverse transcriptase inhibitors on mitochondria in human immunodeficiency virus type 1-infected children receiving highly active antiretroviral therapy. Antimicrob Agents Chemother 2007;51:4236-42.

[98] Tavintharan S, Ong CN, Jeyaseelan K, Sivakumar M, Lim SC, Sum CF. Reduced mitochondrial coenzyme Q10 levels in HepG2 cells treated with high-dose simvastatin: a possible role in statin-induced hepatotoxicity? Toxicol Appl Pharmacol 2007;223:173-9.

[99] Yeh YC, Lai HC, Ting CT, Lee WL, Wang LC, Wang KY, et al. Protection by doxycycline against doxorubicin-induced oxidative stress and apoptosis in mouse testes. Biochem Pharmacol 2007;74:969-80.

[100] Haffor AS, Abou-Tarboush FM. Testicular cellular toxicity of cadmium: transmission electron microscopy examination. J Environ Biol 2004;25:251-8.

[101] Rylova SN, Mirzaee S, Albertioni F, Eriksson S. Expression of deoxynucleoside kinases and 5'-nucleotidases in mouse tissues: implications for mitochondrial toxicity. Biochem Pharmacol 2007;74:169-75.

[102] Nakagawa Y, Moore G. Role of mitochondrial membrane permeability transition in $p$-hydroxybenzoate ester-induced cytotoxicity in rat hepatocytes. Biochem Pharmacol 1999;58:811-6.

[103] Latchoumycandane C, Chitra KC, Mathur PP. The effect of 2,3,7,8tetrachlorodibenzo-p-dioxin on the antioxidant system in mitochondrial and microsomal fractions of rat testis. Toxicology 2002;171:127-35.

[104] Oishi S. Effects of phthalic acid esters on testicular mitochondrial functions in the rat. Arch Toxicol 1990;64:143-7. 